\title{
UM OLHAR SOBRE A SAÚDE MENTAL DOS SOCORRISTAS DO CORPO DE BOMBEIROS DO PARANÁ
}

\author{
A LOOK AT THE MENTAL HEALTH OF THE FIRE DEPARTMENT OF PARANÁ
}

\section{Thiago Haynner Volovicz}

RESUMO: Um trabalho que envolve uma variedade complexa de conhecimentos, responsabilidades técnicas e acionamentos de outros órgãos, aliados a condições adversas como riscos físicos, biológicos, climáticos, dentre outros. Frente a situações de aquartelamentos e vigília que se dá por período de 24 horas contínuos dessa atividade sem interrupção da mesma equipe. Em 2005 foi alterada a Lei de Organização Básica (LOB) da Polícia Militar e o SIATE passou a constar oficialmente da estrutura do Corpo de Bombeiros da Polícia Militar do Paraná. Sendo este feito prestado de extrema responsabilidade e importância aos necessitados. A metodologia adotada no presente trabalho trata-se de uma pesquisa bibliográfica de caráter retrospectivo, abordando publicações entre 2009 a 2019 (Io anos), publicações na língua portuguesa, com busca manual em livros e revistas, foram pesquisados artigos disponíveis na Internet encontrados por meio das bases de dados: BIREME, SCIELO, ADOLEC e BDENF. Os profissionais do atendimento pré-hospitalar convivem com os mais diversos agravos à saúde, envolvendo dor, sofrimento, instabilidade, morte e vida, contribuindo para a ocorrência de ansiedade, tensão, por tempo prolongado de estímulos. Os profissionais do atendimento pré- hospitalar estão no ápice das escalas para desenvolvimento de quadros depressivos e síndromes de transtornos mentais. Diretamente, o estresse ocupacional tem correlação com o aumento dos níveis de depressão, ansiedade, crise de pânico e síndrome de Burnout. Levando assim, muitas das vezes, consequências negativas para a qualidade de vida do profissional Bombeiro Militar. Visto escassez, carência de artigos relacionados e olhares profissionais para com saúde mental desses trabalhadores, o presente estudo tem como objetivo auxiliar os gestores desses profissionais futuramente a buscar didáticas, políticas de trabalho à prevenção, identificação dos potenciais de risco e trabalhos de como manter salubridade no quesito de saúde.

Palavras-Chave: Atendimento Pré-hospitalar. Bombeiros. Estresse Ocupacional. Polícia Militar.

\footnotetext{
I Graduado em Enfermagem - Universidade Filadélfia Londrina - UNIFIL. Pós-Graduado em Urgência e Emergência - Faculdade em Venda Nova do Imigrante - FAVENI. Técnico em Enfermagem - Instituto de Ensino Superior de Londrina-INESUL. Londrina, PR, Brasil. E-mail: goathir4or@gmail.com.
} 
ABSTRACT: A work that involves a complex variety of knowledge, technical responsibilities and actions by other bodies, combined with adverse conditions such as physical, biological, climatic risks, among others. Faced with barracks and vigil situations, that occurs for a non- stoppable 24-hour period of this activity without interruption by the same team. In 2005, the Basic Law of the Military Police (LOB) was changed and SIATE became officially part of the structure of the Fire Department of the Military Police of Paraná. This feat is being rendered of extreme responsibility and importance to the needy. The methodology adopted in the present work is a retrospective bibliographic research, covering publications between 2009 to 2019 (Io years), publications in Portuguese, with manual search in books and magazines, articles available on the Internet were searched through of the databases: BIREME, SCIELO, ADOLEC and BDENF. Prehospital care professionals live with the most diverse health problems, involving pain, suffering, instability, death and life, contributing to the occurrence of anxiety, tension, for a prolonged period of stimuli. Prehospital care professionals are at the apex of the scales for the development of depressive conditions and syndromes of mental disorders. Directly, occupational stress correlates with increased levels of depression, anxiety, panic attacks and Burnout syndrome. So, mostly leading to negative consequences for the quality of life of the professional Military Fire fighter. Given the scarcity, lack of related articles and professional views of these workers' mental health, the present study aims to help the managers of these professionals in the future to seek didactics, prevention work policies, identification of risk potentials and work on how to maintain healthiness in terms of health.

Keywords: Pre-hospital care. Firemen. Occupational Stress. Military police.

\section{INTRODUÇÃO}

Apresentando-se assim até nos dias de hoje. Sendo esta prestação de serviço de extrema responsabilidade e importância aos necessitados. $O$ trabalho envolve uma variedade complexa de conhecimentos técnicos de segurança do trabalho, segurança pública e saúde. Ainda assim envolvendo múltiplas situações que possam ter (acidentes de transportes, acidentes de trabalhos, atendimentos clínicos de emergências como parada cardíaca) com condições adversas para atendimento com riscos físicos, biológicos, químicos, climáticos, dentre outros.

Em 29 de março de 1990 foi assinado o convênio de cooperação técnica, sendo implantado o serviço de atendimento pré-hospitalar de início somente a capital do Estado. Em 2005 sofre alteração a Lei de Organização Básica (LOB) da Polícia Militar e o SIATE passando assim a constar oficialmente da estrutura do Corpo de Bombeiros da Polícia Militar do Paraná.

É comprovado que uma das principais causas de estresse é o trabalho, através de 
estudos, matérias, artigos e pesquisas. Dentre as profissões apontadas com maiores índices de estresse, a emergência pré-hospitalar está praticamente no ápice da lista. Em regra geral, propicia-se que os profissionais que trabalham no atendimento pré-hospitalar, destinam-se apenas a cuidar das doenças e agravos dos outros, não percebendo que eles próprios possam ser afetados por problemas de saúde. Sendo grande parte dos sinais e sintomas de doenças ou síndromes despercebidos, tanto pelo próprio indivíduo como pelos seus próprios companheiros e gestores de trabalhos.

Com isso, o estresse ocupacional tem correlação com o aumento dos níveis de depressão, ansiedade, crise de pânico e síndrome de Burnout. Bem como estado de vigília, sendo essas experiências que precipitam tensão, ansiedade, medo ou ameaça. Acarretando assim muitas das vezes consequências negativas para a qualidade de vida do profissional Bombeiro Militar.

A relevância do assunto é de grau elevado e interesse dentro da corporação. Foi efetuada uma revisão bibliográfica, abordando publicações entre 2009 a 2019 (Io anos), publicações na língua portuguesa, com busca manual em livros e revistas, excluídas teses e monografias, em acervos disponíveis nas bibliotecas da Faculdade. Também foram pesquisados artigos disponíveis na Internet encontrados por meio das bases de dados: BIREME, SCIELO, ADOLEC e BDENF. Os dados foram analisados, comparados e apresentados em forma de texto. Foram feitos as buscas artigos disponíveis na Internet encontrados por meio das bases de dados: Scielo, Adolec e Bdenf e em arquivos da corporação da Polícia Militar.

O objetivo desse trabalho é colaborar que futuramente possa levantar soluções permanentes para profilaxia no desenvolvimento de síndromes e transtornos de ordem psicológica.

\section{DESENVOLVIMENTO}

I.I Atendimento Pré-Hospitalar do Corpo de Bombeiros do Estado do Paraná

O Corpo de Bombeiros do estado do Paraná é um comando intermediário da Polícia Militar (PMPR), com a missão de defesa civil, prevenção e combate a incêndio, buscas, salvamentos e socorros públicos. O Serviço Integrado de Atendimento ao Trauma 
em Emergência (SIATE) é uma atividade prestada pelo Corpo de Bombeiros do Estado do Paraná. Ela tem por objetivo atendimento às vítimas de acidentes, de modo imediato em condições adequadas e ideais de transporte aos hospitais, evitando o agravamento das lesões, manter a vida e evitando complicações ou sequelas de sobrevivência do acidentado.

Em março de 1988 através de uma Portaria da Secretaria de Estado da Saúde, constituiu uma comissão destinada a implantar o projeto piloto. Mais tardar no ano seguinte de 1989 foi implantado o projeto, com o apoio de uma equipe de consultores de Cleveland, Ohio, Estados Unidos. Em 29 de março de 1990 foi assinado o convênio de cooperação técnica, inicialmente somente a capital do Estado. E em 2005 foi alterada a Lei de Organização Básica (LOB) da Polícia Militar e o SIATE (Sistema Atendimento ao Trauma em Emergência) tornou-se oficialmente um componente da estrutura do Corpo de Bombeiros da Polícia Militar do Paraná. São diversos os tipos de situações e ou ocorrências atendidas pelo SIATE, como: Ferimento por arma branca (facas e similares); Agressão; Acidente de trânsito (colisão, atropelamentos e capotamento); Quedas (de mesmo nível ou de nível diferente); Ferimento por arma de fogo; Queimaduras (calor, eletricidade, substâncias químicas); Desabamento/soterramento; e outro traumatismo muitas das vezes associados no mesmo chamado.

Em termos gerais, o primeiro atendimento é realizado por uma viatura ambulância, com uma equipe de bombeiros socorristas e ao ser constatada uma maior gravidade, são mobilizadas outras viatura e solicitado apoio de equipe médica de suporte avançado de vida. Sendo este apoio realizado por equipe SAMU (Serviço de Atendimento Móvel em Urgência). O Socorrista é um bombeiro profissional com formação e treinado através de um curso específico dentro da corporação, para dar suporte básico de atendimento ao trauma. Atuando sob supervisão médica, direta ou à distância, com uso de materiais e equipamentos especializados.

O SIATE é composto por equipes especializadas que estão à disposição da população 24 horas por dia, no Corpo de Bombeiros. Realizando uma escala diurna de uma mesma guarnição em serviços ininterruptos, sem descanso, repouso ou alimentação quando necessário. Por forças maiores as ocorrências conflitarem nos horários estabelecidos. 


\section{ESTRESSE}

Em 1936, Hans Selye, utilizou pela primeira vez o termo estresse que o definiu como um conjunto de reações que um organismo desenvolve esforço de adaptação. Sendo na maioria das vezes como algo negativo, trazendo prejuízo nas atividades afetivas, ocupacionais e sociais do indivíduo. Aponta-se como uma das causas de muitas doenças na sociedade moderna, tais como: hipertensão, infarto agudo do miocárdio, gastrites, alcoolismo, insônia, depressão, entre outras. Em uma situação de estresse emocional acentuado, o metabolismo desencadeia uma produção de hormônios, sendo a adrenalina o principal, que afeta o funcionamento do organismo,

atrapalhando para a diminuição da memória, da capacidade afetiva, concentração, raciocínio, do humor e no mais tardar a capacidade de resolver problemas.

Os especialistas tratam o estresse como uma reação que o indivíduo experimenta (de acordo com suas crenças, valores e cultura) ao criar uma situação que ele não mais consegue suportar, provocando assim manifestações de ordem emocional, social e psicológica. O que percebe-se é que a maioria dos conceitos também envolve o ambiente interno e externo do indivíduo, bem como as situações ou experiências que precipitam tensão, ansiedade, medo ou ameaça, podem ter consequências tanto negativas como positivas, propiciando na maioria dos casos o aumento do estresse (LAUER, 20II).

Observa-se também que não se deve descartar o componente individual do estresse ligado à personalidade e ao modo como a pessoa reage, interpreta e sente os acontecimentos de forma impar à seu indivíduo. Podendo ele atenuar ou tolerar os efeitos prejudiciais do estresse, chamado como coping, definido como sendo as maneiras que o indivíduo desenvolve para enfrentar situações adversas ou situações ditas "estressantes". Alguns mecanismos elencados e utilizados pelos profissionais para enfrentamento do estresse, foram agrupados na seguinte forma: a) lazer: tomar cerveja, festejar, cantar, ver televisão, cuidar de plantas de casa; b) dormir e repouso; c)

atividades junto com família; d) vida social; e) atividade sexual e f) isolamento social.

Cientificamente, o estresse é uma resposta fisiológica, comportamental de um indivíduo se esforçando para adaptar-se e ajustar-se aos estímulos internos e externos 
recebidos. Sendo esse comportamento limitado para a adaptação, que com a persistência do causador estressor, mais cedo ou mais tarde o organismo entrara em esgotamento. Para a física, palavra estresse é utilizada em definir uma força que atua sobre um objeto ou sistema que ultrapassando alguns limites, conduz à deformação ou destruição, sendo ele conceituado em três maneiras: como o estimulo a focalização do impacto causado pelo estressor; como resposta por meio da apreciação da tensão repercutida pelo estressor e como ação entre o ambiente externo e interno do indivíduo pelo processo pessoaambiente. A existência de vários conceitos também dificulta e demora muitas das vezes seu diagnóstico e identificação clara do estresse.

A resposta frente ao estresse tem se ainda sua classificação em duas etapas: síndrome de adaptação geral e síndrome de adaptação local. $\mathrm{Na}$ adaptação geral propriamente dita, refere-se à resposta não específica de defesa e de adaptação orgânica ao estressor, significando uma reação ao estressor, com a mobilização do organismo na procura do restabelecimento da homeostase, desta vez caracterizada novamente por três fases, conforme descrevem Genuino, et al. (2010):

- Fase de alarme: fase de alerta, onde o indivíduo reage uma série de sensações que às vezes não identifica como potencial estressante. Sintomas Esses como mãos suadas, taquipnéia (respiração acelerada), taquicardia (frequência cardíaca elevada), acidez estomacal, inapetência e cefaleia. Relatados na fase aguda.

- Fase da resistência: ocorre quando o indivíduo tenta se adaptar ao estímulo, assim, tentando restabelecer um equilíbrio interno. Conforme a homeostase é atingida, alguns dos sintomas iniciais desaparecerem, porém esse processo de equilíbrio, para sua realização, utiliza energia que o organismo necessita para outras funções vitais.

- Fase da exaustão: nesta fase, toda a energia adaptativa da pessoa foi utilizada, muita das vezes esgotada. Onde os sintomas iniciais reaparecem e outros se desenvolvem, podendo chegar à morte.

Encontrando-se o indivíduo submetido a uma carga excessiva de estressores, o organismo pode desencadear respostas caracterizando no aparecimento de sintomas ou de 
doenças. De acordo com alguns estudos existem profissionais que estão e são mais propensos a desenvolverem o desgaste emocional. A síndrome de Burnout acomete, na grande maioria, profissionais que praticam assistência ou são responsáveis pelo desenvolvimento ou cuidado de outros (BENEVIDE-PEREIRA, 2009).

A vida moderna em muitas das vezes acabam entrelaçando e misturando potenciais e variedades estressoras do trabalho e da vida cotidiana. Além das habituais responsabilidades ocupacionais, a alta competitividade exigida pela instituição de trabalho e das necessidades de atualizações e aprendizado constante, tem que lidar com os estressores normais da vida em sociedade. Ainda assim, a segurança social, a manutenção da família, as exigências culturais, a instabilidade de emprego são algumas variáveis discriminadas. $\mathrm{O}$ tipo de desgaste a que as pessoas estão submetidas nos ambientes e as relações com o trabalho poderão ser fatores determinantes de doenças. Tão logo, o coping seria o mecanismo de defesa a fim de absorver esses impactos.

\subsection{Estresse Ocupacional}

De acordo com artigos consultados o estresse ocupacional refere-se aos estímulos do ambiente de trabalho que exigem resposta. O estresse é um fenômeno atual, sendo estudado e de mais interesse em profissionais como médicos, bombeiros, enfermeiros, professores, psiquiatras, psicólogos e os assistentes sociais. Estes profissionais, lidam diariamente de forma intensa com outros indivíduos e com os seus problemas como objeto de trabalho, sendo assim obrigando-o a uma grande tensão emocional com excessivo esforço de envolvimento pessoal, característico do trato contínuo e exaustivo com outras pessoas. Trabalhadores que desempenham este tipo de tarefas que implicam elevado grau de envolvimento emocional, em geral, não só possui uma maior vulnerabilidade ao stress como maiores níveis de Burnout, muitas vezes por estratégias de enfrentamento ineficazes (AGUIAR et al., 2009).

Sempre que se trata da palavra ocupacional, estamos falando de trabalho, emprego, ocupação, fonte de renda e termos correlatos. Quando pesquisamos as patologias da ocupação, uma das mais proeminentes é o estresse.

A Saúde do Trabalhador constitui um campo na área da Saúde Coletiva, cujo 
objeto está centrado no processo saúde-doença dos trabalhadores dos diversos grupos populacionais em sua relação com o trabalho. Traz consigo a expectativa da compreensão desta dinâmica, bem como do desenvolvimento de alternativas de intervenção com vistas à apropriação da dimensão humana do trabalho pelos próprios trabalhadores. Busca, portanto, estabelecer causas de agravos à sua saúde, reconhecer seus determinantes, estimar riscos, dar a conhecer os modos de prevenção e promover saúde (MENDES; DIAS, 2009).

Estudos indicam que o ambiente de trabalho, as estruturas corporativas e diversas outras interações entre emprego e empregado contribuem para as respostas individuais de estresse e tensão. Consequentemente, a organização acaba tendo problemas de desempenho ruim, baixa moral, alta rotatividade, absenteísmo e violência no local de trabalho.

Dentre as profissões elencadas com maiores índices de estresse, a emergência préhospitalar está praticamente no topo da lista. E ainda assim em regra geral, tendemos a pensar que os profissionais do atendimento pré-hospitalar e a exposição contínua a fatores do trabalho, que são considerados como desprazerosos pelo profissional, o conduz a um desgaste físico e emocional que, em um primeiro momento, aparece sob forma de estresse. Entretanto, a manutenção dessa situação no trabalho proporcionará um estresse crônico, exigindo do sujeito que acione mecanismos adaptativos, que por vezes não são eficazes,

Diante do cenário da prestação de serviços de emergência médica, os profissionais do setor dessa área são submetidos, constantemente, à sobrecarga de trabalho mental, psíquica e física, além de pressão para tomada de decisões rápidas, fundamentais no atendimento de emergência. Ainda, as jornadas de trabalho são extenuantes, dado o volume de usuários e a reposição de energia dos trabalhadores. Os socorristas militares se deparam com diversas situações trágicas, aliadas à necessidade de saber lidar de forma eficiente e eficaz, com as necessidades das vítimas. Esses profissionais convivem com os mais diversos agravos à saúde, envolvendo dor, sofrimento, instabilidade, morte e vida, contribuindo para a ocorrência de ansiedade, tensão, posteriormente podendo evoluir para o estresse (FERNANDES et al. 2009).

O estimulo estressor é definido como uma situação ou experiência que gera 
sentimentos de tensão, ansiedade, medo ou ameaça, que pode ter origem interna ou externa. Assim, o estresse sendo um fenômeno complexo e dinâmico, merece atenção especial dos profissionais da saúde, tendo a clareza de que por mais que a subjetividade e a percepção sejam pioneiras no desencadeamento de estresse, as condições de trabalho exercem influência significativa para seu agravo. Como exemplo prático, pode-se citar a chamada a Síndrome de Burnout, termo cunhado pelo psicanalista Hebert J. Fredenberg na década de 1970. Segundo Andrade e Cardoso (2012) dizem que tratam-se de uma síndrome psicológica que envolve uma reação prolongada aos estressores interpessoais e significa queimar-se por completo ou consumir-se. As três principais dimensões desta reação são uma exaustão avassaladora, sensação de ceticismo e desligamento do trabalho, uma sensação de ineficiência e falta de realização.

Hebert (1970) observou e constatou em si mesmo e em amigos que o trabalho que antes era uma atividade prazerosa, começou a deixa-los cansados e frustrados. Ao voltar à atenção a outras profissões encontrou problemas como oscilações de humor, distúrbios do sono, dificuldades de concentração, sintomas físicos e distúrbios digestivos.

Fatores organizacionais afetam a qualidade de vida como sobrecarga de trabalho, a falta de adaptação, a falta de estímulo que pode levar ao tédio, sensação de solidão, ruídos/barulhos intensos onde pode alterar o sono e viagens de trabalho. $\mathrm{O}$ momento presente está quase sempre exigindo mudanças e com isso trazendo novos problemas, mudanças determinadas pela empresa podem causar frustações.

A depressão no trabalho é outro exemplo da ausência de práticas efetivas de qualidade de vida no ambiente laboral, uma vez que as pessoas muitas vezes levam trabalho para casa, atendem ligações em qualquer horário para falar de assuntos profissionais... As pessoas não têm mais tempo disponíveis para o laser. A falta de identificação com a "profissão escolhida, metas a serem atingida, cobrança do chefe, excesso de trabalho, sonhos e expectativas de promoções que nunca chegam” são os principais motivos relacionados com a depressão no trabalho. $\mathrm{O}$ profissional começa a se ver como um fracasso e ter perspectiva negativa quanto ao seu cargo, além de se afastar das pessoas (GARCIA, 2oro, p. 76-94).

Podendo ter consequências negativas para a qualidade de vida do profissional 
Bombeiro Militar dia após dia, diurnamente em escalas ininterruptas de $24 \mathrm{~h}$ dentro de ambiente de serviço com folgas de 48 horas, estes profissionais se deparam com situações de grande complexidade, relatando, após o atendimento, uma variedade de fatores, incluindo a exposição a incidentes traumáticos. Este mal vem interferindo na vida dos profissionais da área, comprometendo a vida social e sua saúde, prejudicando na atuação do trabalho emergencial, segundo artigos levantados nesse trabalho.

Para Junior (2012) a profissão de bombeiro é uma das profissões de ajuda mais exigentes. As condições de trabalho englobam tudo que influencia o próprio trabalho. Envolvendo não apenas do posto de trabalho e seu ambiente, como também das relações entre salário; duração da jornada; dos horários de trabalho; do repouso e alimentação; entre outras. Considerada uma profissão de risco pela natureza das suas funções, os bombeiros são confrontados, na sua prática diária, com situações limite, muitas vezes envolvendo graves danos pessoais e materiais, em função das quais os recursos emocionais disponíveis são postos à prova de forma dramática.

Estas situações, pela sua frequência são eventualmente indutoras de elevados níveis de estresse e, quando continuadas, de Burnout. Sabe-se, por outro lado, que estes fenômenos psicológicos têm um impacto negativo a vários níveis do funcionamento pessoal implicando tanto a eficácia dos serviços prestados, como a saúde física e psicológica desses profissionais (BENEVIDE-PEREIRA, 2009).

Os bombeiros são atualmente a maior e mais ativa comunidade de cidadãos unidos por um ideal, trabalhando de dia e de noite, muitas vezes de forma voluntária, e ou convocados em missões que tem como objetivo a proteção de pessoas, dos bens e do ambiente, prevenindo situações que as ponham em perigo minimizando as suas consequências. Face às inumeráveis situações em que se torna necessária a intervenção dos bombeiros, as missões de proteção e socorro que lhes são confiadas impõem não só uma formação, mas também implicam preparação e intervenção nas mais diversas situações FERRARI, 2019).

Destas destacam-se as missões de socorro às vítimas de acidentes automobilísticos, as urgências e emergências pré-hospitalares, o combate a incêndios (florestais, urbanos e indústrias), a intervenção em enchentes e inundações, assim como outras situações de 
emergências em que vidas ou bens estejam em perigo. Estas missões são realizadas, muitas vezes com escassez de meios disponíveis e intensos níveis de dramatismo envolvidos nas suas atividades cotidianas.

Os sujeitos com mais propensão para desenvolver Burnout são os mais dedicados e empenhados, os que se envolvem de forma mais intensa no seu trabalho e são mais idealistas e motivados. Esta descrição parece encaixar de forma perfeita nos bombeiros, como profissionais de ajuda, independentemente das variações individuais. Apesar disso existem relativamente poucos trabalhos científicos que se tenham proposto a abordar num mesmo estudo o estresse e seu enfrentamento (coping, burnout e o hardiness) nestes profissionais (MASLACH et al., 2014). De acordo com o Ministério da Previdência, os acidentários concedidos em outubro de 2020 foi de 390,2 mil benefícios dos auxíliosdoença, baseados na categoria "Transtornos Mentais e Comportamentais", referem-se a problemas como estresse, episódios depressivos, alternância de humor e ansiedade. Os maiores problemas, conforme listou o ministério, episódios depressivos e estresses são as doenças mais identificadas nos trabalhadores. A cronificação do estresse ocupacional leva à síndrome de Burnout. A palavra significa exaustão, queimar-se por completo. Trata-se de uma fase aguda da manifestação do estresse, caracterizando-se pelo cansaço e esgotamento emocional, pela despersonalização e pela diminuição da realização pessoal, com uma auto avaliação negativa de si mesmo (MASLACH; GOLBERG, 2012).

Vários profissionais estão sujeitos a adquirir o estresse negativo, contudo, o cotidiano dos profissionais do atendimento pré-hospitalar do corpo de bombeiro militar, a escala de serviço de 24 horas trabalhadas por 48 horas de folga, onde o bombeiro militar muitas das vezes tiram escalas extras e/ou extraordinárias, bem como as trocas de serviços entre militares. Tem causado pouco tempo destinado ao descanso (trabalhando mais de 40 horas semanais), comprometendo a saúde mental destes profissionais, acarretando problemas nas relações interpessoais e no desempenho de suas atividades profissionais de bombeiro militar, em especial o socorrista (VASCONCELOS, 2010)..

A atuação destas equipes se dá em um ambiente carregado de fatores estressantes, tanto físicos quanto psicológicos. Está praticamente a todo o momento se relacionando com pessoas, ouvindo suas aflições, insatisfações e necessidades. Tudo isso gera um 
desgaste nesse profissional que fica em completo estado de exaustão emocional passando a adquirir atitudes negativas a respeito do seu trabalho, diminuindo assim o seu envolvimento pessoal na função que exerce, acabando por prejudicar a instituição onde o mesmo serve. Várias definições existem a respeito desse estresse crônico, porém a definição mais aceita atualmente fundamenta-se na perspectiva social-psicológica que: $O$ mito do herói, alimentado pela mídia na exploração das ocorrências e pelas corporações em seu preparo do profissional, deve ser levado em conta como uma perigosa armadilha para a saúde e a vida deste profissional (BENEVIDES-PEREIRA, 2009).

Considera a síndrome como uma reação à tensão emocional crônica por lidar excessivamente com pessoas. É um construto formado por três dimensões relacionadas, mas independentes. Exaustão Emocional, caracterizada pela falta ou carência de energia e entusiasmo e sentimento de esgotamento de recursos. A estes sentimentos soma-se o de frustração e tensão, pois os trabalhadores passam a perceber que já não possuem condições de despender mais energia para o atendimento de seu cliente ou demais pessoas como faziam anteriormente. Ninguém conhece tão bem os problemas na rotina dos atendimentos pré-hospitalares quanto os próprios bombeiros socorristas militares. Na luta para salvar vidas, eles muitas vezes se desdobram para superar esses obstáculos (MASLACH; GOLBERG, 2012).

\section{CONCLUSÃO}

As revisões bibliográficas realizadas neste trabalho no tocante do trabalho de bombeiros militares do estado do Paraná, voltados em especialmente aos profissionais socorristas de atendimento pré-hospitalar. Relacionados ao estresse ocupacional, síndromes de ordem psicológica e enfrentamento das desordens até ao momento, são poucas, associado ao fato da comunidade científica e gestores não ter ainda dedicado a atenção merecida a estes profissionais. Pela escassez de trabalhos encontrados na área, dada a importância das atividades que desempenham, a natureza das situações com que se deparam os bombeiros, cremos ser de extrema importância, tanto a nível social como científico, gestores desses profissionais empenharmo-nos sobre nossa população bombeiros militares socorristas. Efetuando uma análise científica mais aprofundada, 
principalmente no que diz respeito aos fenômenos relacionados ao estresse, dado o impacto social que provocam e os prejuízos associados.

O estresse elevado que esses profissionais de atendimento pré-hospitalar estão expostos no seu dia a dia de trabalho, monstra que são um grupo ocupacional que necessita de programas de manejo de estresse ocupacional. Tais programas variam enormemente quanto ao foco, incluindo intervenções propriamente no indivíduo, no trabalho, e intervenções combinadas.

Finalmente, este trabalho científico validou a relação direta entre a atividade do corpo de bombeiros, estresse ocupacional (do profissional socorrista Bombeiro Militar). E sofrem diversas influências que dificultam diagnóstico do grau de estresse que encontrasse cada indivíduo. O exemplo de mitos de heroísmo e sentimento de envolvimento no cumprimento do dever. Tal concepção para a população e até mesmo do indivíduo mesmo antes de tornar-se um bombeiro militar, que por muitas das vezes também tinha essa concepção e constantemente podendo aparecer em seu processo formação para introdução na corporação, reforçando essas características de autoajuda e cura cabendo o indivíduo suportar ou próprio diagnosticar-se e procurar ajuda de forma espontânea por não ter nenhuma ou pouca atividade de diagnostico ou avaliação de grau de estresse dentro da corporação para estes. O estresse ocupacional em Bombeiros Militares tem nível mais elevado quando comparado às outras profissões.

Levando-se em consideração os resultados e conclusões deste trabalho, ficou evidenciado que os profissionais de atendimento pré-hospitalar, convivem diuturnamente com elementos de estresse ocupacional, merecendo uma maior atenção por parte de seus comandantes e/ou gestores, para um melhor enfrentamento destes problemas evitando futuros agravos de saúde que possam prejudicar a pessoa com reflexos na instituição. Com os resultados obtidos na realização deste trabalho, assim como o conhecimento adquirido no desenvolvimento do estudo, podem-se sugerir trabalhos a serem desenvolvidos para outras variáveis ainda não avaliadas neste estudo como forma de incentivo ao estudo e pesquisa sobre o tema. E ainda, que outras investigações sejam necessárias, como o problema da escala de serviço alternante, dobra de serviço e escalas extras e/ou extraordinárias, que é uma prática frequente entre estes profissionais. 


\section{REFERÊNCIAS}

AGUIAR, K. N. D. et al. O estresse em uma equipe militar de resgate pré-hospitalar. Revista Eletrônica de Enfermagem, v. 2, n. 2, I5 dez. 2006.

ANDRADE, P. S; CARDOSO, T. A. O. Prazer e Dor na Docência: revisão bibliográfica sobre a Síndrome de Burnout. Saúde Soc. São Paulo, v.21, n.I, p.129-I40, 2012. Disponível em: $\langle$ http://www.scielo.br/pdf/sausoc/v2InI/I3.pdf >. Acesso em: 20 de fevereiro de 2015 .

BENEVIDE-PEREIRA, A. M. B. Burnout: quando o bem-estar ameaça a saúde do trabalhador. São Paulo, Casa do Psicólogo, 2009

EVANGELISTA, A. Profissionais de urgência e emergência convivem com agentes estressores que podem e devem ser eliminados e amenizados. Redação da revista emergência, Rio Grande do Sul, Edição Abril/2o12. Disponível em:<http://www.revistaemergencia.com.br. Acesso em: io dez.2020. FERNANDES, S. et al. Estresse ocupacional e o mundo do trabalho atual: repercussões na vidacotidiana das enfermeiras. Revista Eletrônica de Enfermagem, v. Io, n. 2, 2 nov. 2009.

FERRARI, J.S. "Estresse Ocupacional"; Brasil Escola. Disponível em: https://brasilescola.uol.com.br/psicologia/stress-ocupacional.htm. Acesso em Io.dez.202o.

GENUINO, S.L.V. et al. O estresse ocupacional e a Síndrome de Burnout no ambiente de trabalho: suas influências no comportamento dos professores da rede privada do ensino médio de João Pessoa. Rev Anagrama. 2010; 2:1-9.

JUNIOR, W.L. Estresse ocupacional do bombeiro militar: Uma realidade no atendimento pré- hospitalar. Universidade Estadual de Goiás. 2012. Disponível em: http://www.bombeiros.go.gov.br/wp-content/uploads/2013/o2/Estress-Ocupacional.pdf.

Acesso em: 03 dez.2020.

LAUER, Caio. As doenças ocupacionais nas corporações. Carreira \& Sucesso. I7/o4/20Ir.Disponível:http://www.catho.com.br/jcs/inputer_view.phtml?id=12473, em: acesso em: $25 / \mathrm{set} / 2019$.

MASLACH, C.; SCHAUfEli, W.B. LEITER, M. P. Job burnout. Annual Review Psychology, 52, 397-422, 2014.

MENDES, R.; DIAS, E. C. Saúde dos trabalhadores. In: ROUQUAYROL, M. Z.; ALMEIDA FILHO, N. Epidemiologia e saúde. Rio de Janeiro: MEDSI, 2009. p. 431-458.

VASCONCELOS, E. R. Comentários ao código disciplinar dos militares estaduais. 2.ed. Fortaleza: Realce, 2010. 